\title{
Disentangling Darwin
}

\author{
Jason R Ali discusses oceanic \\ island subsidence and the \\ shaping of biodiversity on the \\ Galápagos archipelago - or what \\ Darwin missed.
}

$\mathrm{P}$ hysical processes including eustatic sea-level fluctuations, cooling-related subsidence and isostasy have together profoundly shaped the geographical distribution and evolutionary trajectories of the land-locked biota on the Galápagos archipelago in the eastern equatorial Pacific. In the recent geological past, several islands in the centre and west of the chain regularly coalesced into a single platform for 5000-10000-year intervals, having previously been separated for $\sim 90000$-year periods. In the Origin of Species, Darwin notably rejected any idea that the ocean floor separating the various islands in Galápagos had ever been sub-aerial, and thus assumed that former land-bridges had played no role in the biological story. Intriguingly, however, in earlier works on coral reef formation and growth, Darwin $(1837,1842)$ introduced the concept of oceanic island subsidence to explain atolls, and was amenable to $1500 \mathrm{~m}$ of downward displacement. This article attempts to explain why Darwin failed to join the dots.

Following the revolution that established plate tectonic theory in the 1960s and 1970s (Dewey 2015), we now recognize that midocean-ridge-generated lithosphere steadily sinks as it ages and cools (Parsons \& Sclater 1977, Hillier \& Watts 2005). The relationship can be summarized using the empirically derived equation $z=A+\left(B t^{1 / 2}\right)$, where $z$ is the depth of the crust at a particular instant, $A$ is the depth at which the ridge forms (typically 2500-2800 m), and $t$ is the crustal age in millions of years (Ma). The relatively recent work of Hillier (2010) set $B$ as 329, thus 10 million years after its formation the ocean floor will have descended by a fraction over $1 \mathrm{~km}$ (figure 1). In cases where oceanic lithosphere subsequently migrates over a mantle hot-spot, which might result in seabed volcanism that sometimes creates islands, it is thought that the subsidence path is reset (Detrick $e t$

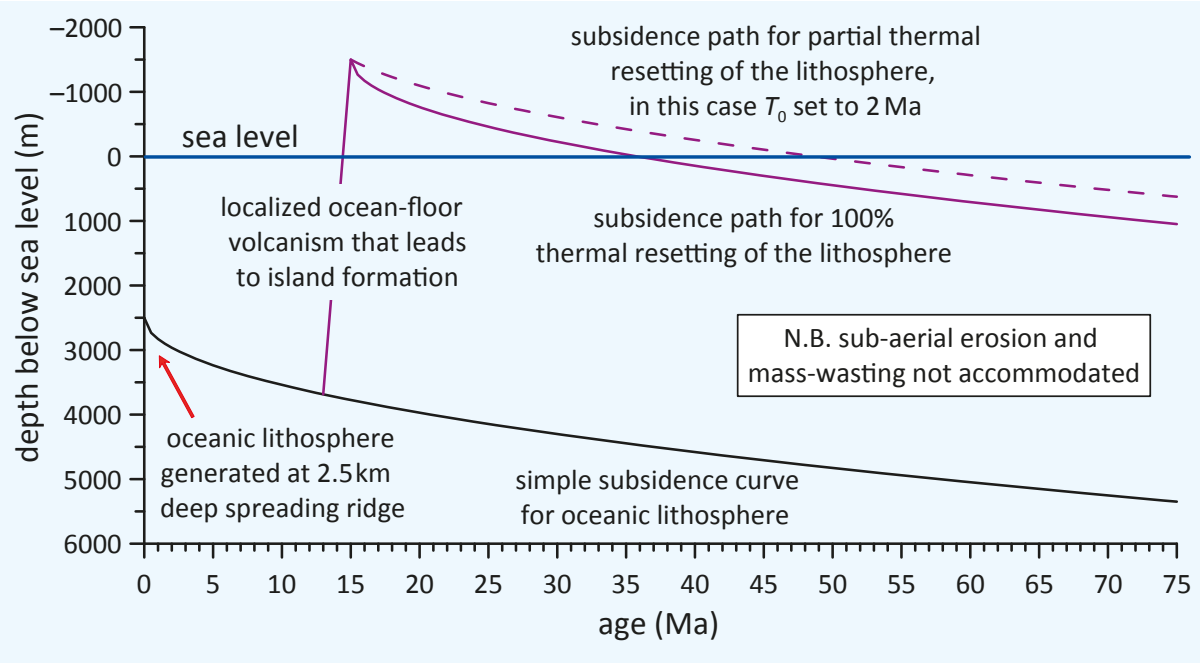

1 Subsidence paths of mid-ocean-ridge-generated lithosphere and oceanic islands that are generated later as the plate moves over a mantle hot-spot.

al. 1977, Detrick \& Crough 1978, Scoffin \& Dixon 1983; Clift 2005, though, has argued that the processes may not always be $100 \%$ effective). The mechanism, alongside subaerial erosion and mass-wasting, accounts for the oldest islands exposing volcanic bedrock (as opposed to those with carbonate reef caps) typically being younger than $5-15$ million years, for instance in the Hawaii group (Clague \& Dalrymple 1987) or the Mascarene chain (Duncan \& Hargraves 1990).

\section{Galápagos biological laboratory}

Over the past 150 years, the biota on the Galápagos archipelago has fundamentally informed understanding of biological processes, in particular the principal mechanism by which life has evolved (natural selection), as well as how new frontiers are colonized (Darwin 1859, Rassmann 1997, Grant \& Grant 2008, Parent et al. 2008). Recent paleogeographic modelling of the chain by Ali \& Aitchison (2014) suggests that, over the past 700000 years, oscillations in local relative sea level modified dramatically the areal extent of many of the Galápagos islands and, in doing so, markedly shaped the evolutionary pathways of the bulk of the land-bound reptile species.

The shifts in coastline arose from the cumulative effect of three processes:
- eustatic sea-level changes induced by icesheet growth and retreat;

- vertical displacements of the archipelago from changes in water column load on the seabed caused by eustatic fluctuations;

- oceanic island thermal-cooling For 150 ....... subsidence (conservatively there has informed set at $105 \mathrm{~m}$ over the past million years).

Over multiple cycles lasting around 100000 years, sea levels on Galápagos ranged thus share genetic material. How much they could have mixed was also controlled by the range expansion abilities of each of the forms during the sea-level nadirs: limited for lava lizards, leaf-tailed geckos and land iguanas, but widespread for racer snakes.

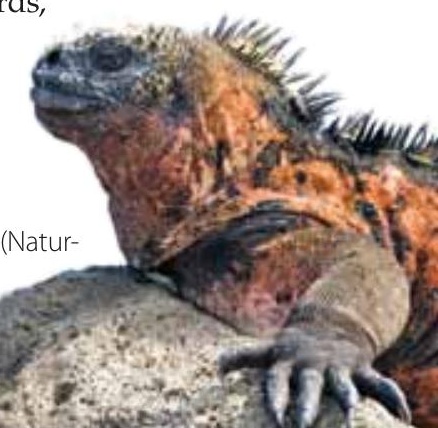



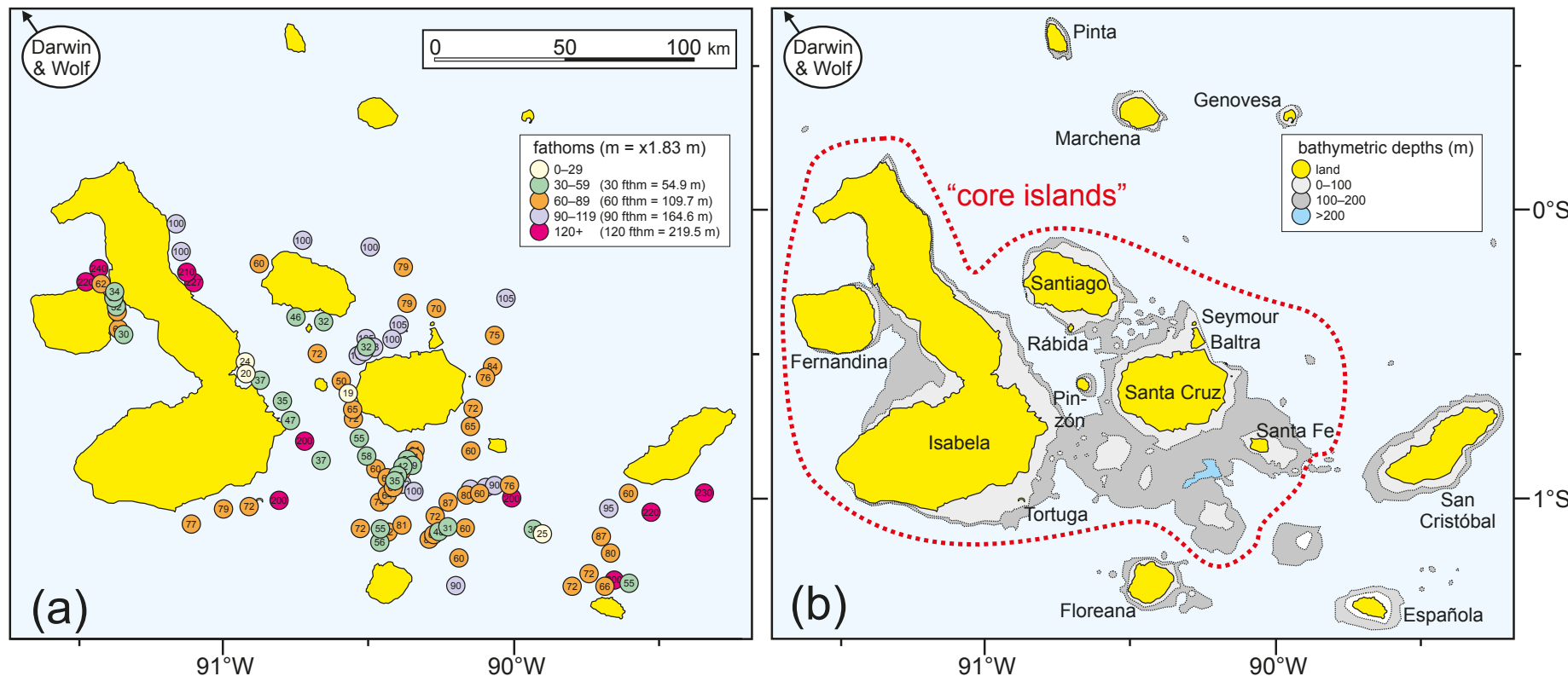

3 Bathymetric charts for the Galápagos archipelago. Image (a) shows the chain with the offshore depth soundings (in fathoms) around the main islands that were made by Robert Fitzroy and the Beagle officers (Fitzroy et al. 1841). To avoid clutter, the numerous coastal readings are not depicted. Note that, compared to a modern chart, the one generated by Fitzroy and his men is slightly "out"; for instance, prominent geographical features are offset by about 5 arcmin $(\sim 9.3 \mathrm{~km})$ to the west of the $91^{\circ} \mathrm{W}$ and $90^{\circ} \mathrm{W}$ meridians; some of the islands are not in the exact relative positions; the northern end of Isabela is rotated counterclockwise slightly, etc. Consequently, the locations of the depth soundings are best estimates. Map (b) is based on a UK Admiralty chart (2006) and an output from the GMAP online plotting software (Ryan et al. 2009). Ali \& Aitchison's (2014) "core" islands are also highlighted.

\section{Darwin and Galápagos}

Galápagos formed the basis of important elements of Darwin's (1859) theorizing on natural selection. The archipelago and its fauna featured prominently in the second of his chapters on geographical distributions (chapter 12). Our findings (Ali \& Aitchison 2014), in particular the thermal subsidence correction we suggested should be applied ( $105 \mathrm{~m}$ for the past million years, although values up to $329 \mathrm{~m}$ may be possible), focus attention on the fact that although Darwin recognized that representatives of species were present on a number of islands, he explicitly excluded the possibility that the intervening sea floor had ever been sub-aerial. In three known the seabed
separating the islands
was relatively shallow" sentences, he eliminated any role for landbridges in moulding the biogeographical patterns, and consequently the evolutionary development of the biota (Darwin 1959):

"But the islands, though in sight of each other, are separated by deep arms of the sea, in most cases wider than the British Channel, and there is no reason to suppose that they have at any former period been continuously united. The currents of the sea are rapid and sweep across the archipelago, and gales of wind are extraordinarily rare; so that the islands are far more effectually separated from each other than they appear to be on a map. Nevertheless a good many species, both those found in other parts of the world and those confined to the archipelago, are common to the several islands, and we may infer from certain facts that these have probably spread from some one island to the others."
Based on Darwin's experiences and the topics on which he had previously published, however, such a position is odd. First, at least two decades before Origin of Species (1859), Darwin had presented his ideas on coral reef formation and growth (1837, 1842). Concerning atolls, for which Darwin's model has long been regarded as the textbook explanation (Rosen 1982), he hypothesized that the carbonate structures developed on the upper flanks of extinct volcanoes that were steadily subsiding, as well as being eroded. Although Darwin did not know the causal mechanism or the rates at which volcanoes sank, his arguments and illustrations suggest that the vertical displacements could be a few thousand feet or more (Darwin 1842), that is, well over a kilometre. Secondly, during the time Fitzroy and the Beagle party were working their way through the chain (Grant \& Estes 2009) collecting data for their Galápagos chart (published as Fitzroy et al. 1841), Darwin must have become aware that the seabed separating the central and western islands was relatively shallow, just 30-100 fathoms (55-183 m) (figure 1). Therefore, his notion of "deep arms of the sea" is incorrect.

These water depths are also at odds with his view in which thousands of feet of subsidence might be associated with oceanic island atoll growth (without a mechanism for subsequent uplift). Significantly, in an 1842 letter to Sir Charles Lyell, Darwin envisaged that seamount subsidence could be as great as 5000 feet
$(>1500 \mathrm{~m})$ in this area (Darwin \& Seward 1903, Stoddart 1976).

\section{What influenced Darwin's thinking?} Why might Darwin have concluded that the islands in the Galápagos had never been connected by land-bridges? Firstly, Darwin's understanding of oceanic islands was incomplete. In modern-day plate tectonic theory, volcanic islands develop in two types of oceanic setting. The first grow over mantle hot-spots (figure $5 \mathrm{a}$ ), examples of which include the Canaries, Hawaii, Maldives and Galápagos. The second form above intra-oceanic subduction zones (figure 5b), for instance Lesser Antilles, South Sandwich, Bonins and various parts of offshore SE Asia. Tectonically, the latter are much more active, being marked by moderate and large earthquakes (http:// earthquake.usgs.gov/earthquakes/ world/seismicity_maps/world.pdf); they sit adjacent to a plate boundary where oceanic lithosphere is being recycled back into the mantle. Darwin was unaware of this difference. Critically, Darwin's atolls formed on islands where volcanism had ceased and subsidence was steady, thus excluding geodynamically active regions such as the East Indies and West Indies (Darwin 1837, 1842, 1844). Notably, the two westernmost islands in Galápagos, Fernandina and Isabela, are volcanic, the latter comprising five separate eruptive centres. This is probably why Darwin assumed the archipelago was not subsiding. That said, eruptions do not take place on any of the other islands, either in the core of the archipelago or beyond: Wolf 


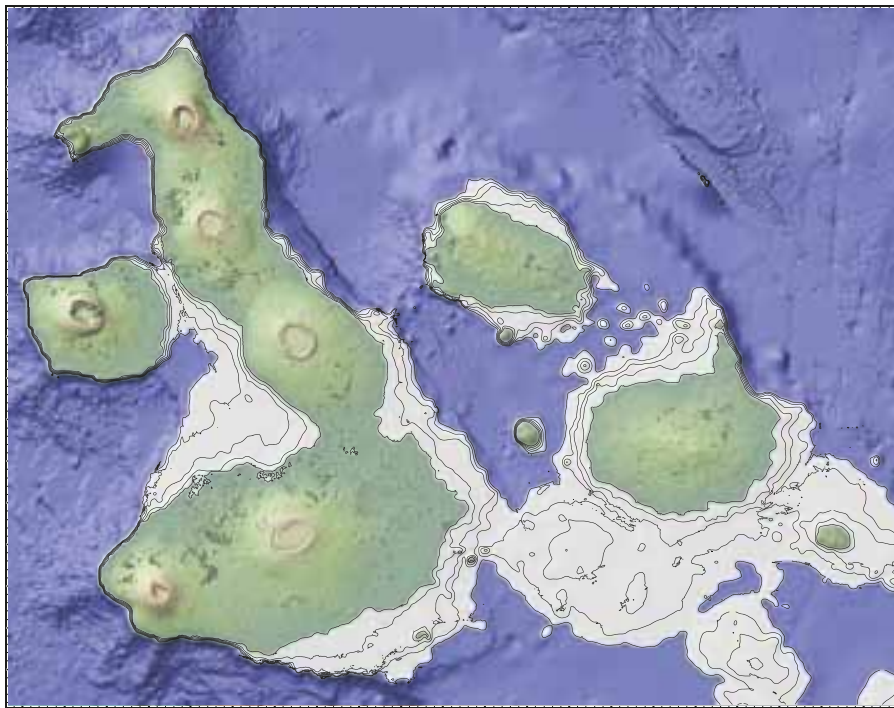

4 Bathymetric-topographic map of the central and western islands of the Galápagos archipelago ("core" islands of Ali \& Aitchison 2014). The image was generated using the GMAP software (Ryan et al. 2009). Grey-shaded areas represent the $0 \mathrm{~m}$ to $200 \mathrm{~m}$ depth interval; isobaths are shown for $50 \mathrm{~m}$, $100 \mathrm{~m}, 150 \mathrm{~m}$ and $200 \mathrm{~m}$. Note also the active volcanic craters on the two westernmost islands, Fernandina (one) and Isabela (five) - names of all of the islands are included in figure 3.

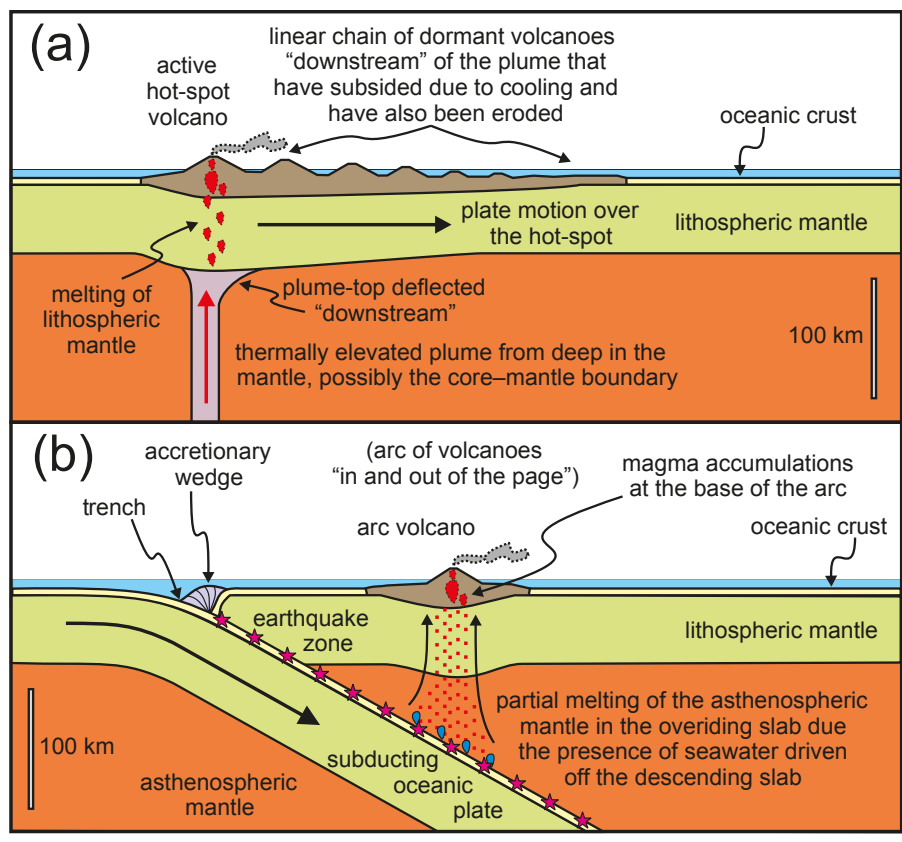

5 How oceanic islands form and develop due to volcanism: (a) above a mantle plume hot-spot, (b) above an intra-oceanic subduction zone. In (b), frequent earthquakes (stars) are associated with sporadic rapid movements between the upper and lower plates. (From online sources, including US Geological Survey site http://www.uic.edu/classes/psych/psych353/role/typespb.html) and Darwin to the north-northwest; Pinta, Marchena and Genovosa to the north and northeast; or on Española, San Cristóbal and Floreana to the south and east.

\section{Incomplete survey}

Secondly, Darwin's statement hints that the archipelago's faunal suite was thoroughly sampled and documented. However, the reptile database available to him (Bell 1843) was far from complete. If it had been a comprehensive survey, it is entirely possible that Darwin would have pre-empted John Van Denburgh who, based on the reptileoccurrence records, a century ago postulated a radical paleogeographical model for the Galápagos islands. As herpetology curator at the California Academy of Sciences, Van Denburgh described and catalogued the specimens collected during the institute's 17-month expedition in 1905-6; for comparison, the Beagle's visit lasted just five weeks. Notably, Van Denburgh recognized common species of leaf-toed gecko (Van Denburgh 1912) and lava lizards (Van Denburgh \& Slevin 1913) on the central and western islands, with congeneric forms on the peripheral ones. Moreover, an almost identical pattern is shown by two racer-snake species and land iguanas. This led him to propose that the islands had formerly been part of a single terrain that had originally been connected to the Americas via a vast causeway. Initially, the land-bridge to the mainland sundered. Later the reptile sub-populations on each of the islands were isolated due to differential subsidence sporadically drowning portions of the platform. A middle-stage geographical configuration saw the core group, as defined by Ali \& Aitchison (2014), separate from the others; figure 8 in Wright
(1983) provides a useful schematic. Note that the scenario differs from that of Ali \& Aitchison (2014) where, during the late Quaternary, the core islands experienced numerous cycles of extended isolation then short-lived connectivity.

Famously, Darwin was able "to connect the dots" (e.g. Darwin 1842, 1859), his ........... mind "a kind of machine for "His mind was a machine grinding general laws out for grinding general of large collections of facts" laws out of large collections of facts"

(Darwin 1958). However, given the role oceanic island thermal subsidence played in forging biodiversity on Galápagos, it would be unjust to say that he missed the link. The overall lack of geological, geophysical and biological information and insight that might have encouraged him to explore the idea was, in the mid-19th century, simply unavailable. $\bullet$

\section{AUTHOR \\ Jason R Ali, Dept of Earth Sciences, University of} Hong Kong, China; jrali@hku.hk.

\section{ACKNOWLEDGMENTS}

Jonathan Aitchison, Peter Cunich, Peter Flood and Ron Hill are thanked for their comments on drafts and/or general discussions.

\section{REFERENCES}

Ali JR \& Aitchison JC 2014 J. Biogeogr. 411227 Bell T 1843 The Zoology of the Voyage of H.M.S. Beagle under the Command of Captain Fitzroy, R.N. during the Years 1832 to 1836. Part V. Reptiles (Smith Elder and Co, London)

Clague D A \& Dalrymple GB 1987 United States Geol. Surv Prof Pap 1350

Clift PD 2005 Geol. Soc. Amer. Spec. Pap. 388279

Darwin CR 1837 Proc. Geol. Soc. Lond. 2552

Darwin CR 1842 The Structure and Distribution of
Coral Reefs. Being the First Part of the Geology of the Voyage of the Beagle, under the Command of Capt. Fitzroy, R.N. during the Years 1832 to 1836 (Smith, Elder and Co., London)

Darwin CR 1844 Geological Observations on the Volcanic Islands Visited during the Voyage of H.M.S. Beagle, together with some Brief Notices of the Geology of Australia and the Cape of Good Hope. Being the Second Part of the Geology of the Voyage of the Beagle, under the Command of Capt. Fitzroy, R.N. during the Years 1832 and 1836 (Smith, Elder and Co., London)

Darwin CR 1859 The Origin of Species by Means of Natural Selection, or, the Preservation of Favoured Races in the Struggle for Life (John Murray, London) Darwin CR 1861 The Origin of Species by Means of Natural Selection, or the Preservation of Favoured Races in the Struggle for Life 3rd edn (John Murray, London)

Darwin CR 1958 The Autobiography of Charles
Darwin, 1809-1882 (WW Norton, New York)

Darwin F \& Seward AC (eds.) 1903 More Letters of Charles Darwin. A Record of his Work in a Series of Hitherto Unpublished Letters, Volume II (John Murray, London)

Detrick RS \& Crough ST 1978 J. Geophys. Res. 83B 1236

Detrick RS et al. 1977 Earth Planet. Sci. Lett. 34185 Dewey JF 2015 Phil. Trans. R. Soc. A 37320140227 Duncan RA \& Hargraves RB 1990 Proc. Ocean Drill. Prog. Sci. Res. 11543

Fitzroy R et al. 1841 Galapagos Islands (Hydrographic Office of the Admiralty, London) Grant PR \& Grant BR 2008 How and Why Species Multiply: the Radiation of Darwin's Finches (Princeton University Press, Princeton) Grant TK \& Estes G 2009 Darwin in Galápagos

(Princeton University Press, Princeton) Hillier JK 2010 J. Geophys. Res. 115B B03102 Hillier JK \& Watts AB 2005 J. Geophys. Res. 110B
B02405

Parent CE et al. 2008 Phil. Trans. Roy. Soc. Lond. B 3633347

Parsons B \& Sclater JG 1977 」 Geophys. Res. 82B 803

Rassmann K 1997 Mol. Phyl.Evol. 7158

Rosen BR 1982 BioScience 32519

Ryan WBF et al. 2009 Geochem., Geophys. Geosyst. 10 Q03014

Scoffin TP \& Dixon JE 1983 Biol. J. Linnean Soc. 2011 Stoddart DR 1976 The Brit. J. Hist. Sci. 9199 UK Admiralty 2006 Archipiélago de Colón (Galapagos Islands), 4th edn (1:750,000) (UK Hydrographic Office, Taunton)

Van Denburgh J 1912 Proc. Calif. Acad. Sci. 4-1 405 Van Denburgh J \& Slevin JR 1913 Proc. Calif. Acad. Sci. 4-2 132

Wright JW 1983 Patterns of Evolution in Galápagos Organisms Bowman RI, Berson M, Levinton AE (eds) (Am. Assoc. Adv. Sci., San Francisco) 123 